\title{
Innovative clothing system for protection against perforation
}

\author{
G. Santos ${ }^{1, *}$, R. Marques ${ }^{1}$, M. Pinto ${ }^{2}$, F. Pinheiro ${ }^{3}$, P. Ferreira ${ }^{4}$ \\ ${ }^{1}$ CITEVE - Technological Center for the Textile and Clothing Industries of Portugal, V. N. Famalicao, Portugal \\ ${ }^{2}$ LEMAR - Leandro Magalhaes de Araujo (Filhos), Lda., Guimaraes, Portugal \\ 3 OLDTRADING S.A., V. N. Famalicao, Portugal \\ ${ }^{4}$ DAMEL - Confeccao de Vestuario Lda., Povoa de Varzim, Portugal \\ *Corresponding author E-mail address: gsantos@citeve.pt
}

\section{INFO}

CDAPT, ISSN 2701-939X

Peer reviewed article

2020, Vol. 1, No. 2, pp. 121-129

DOI 10.25367/cdatp.2020.1.p121-129

Received: 30 July 2020

Accepted: 31 October 2020

Available online: 3 December 2020

\begin{abstract}
Opuntia ficus-indica is a cactus species that has a large potential in several applications. Despite its enormous potential, the production process is still a concern. The harvest process is still mostly manual and implies a dangerous exposure of the human being not only to harsh environmental conditions such as high temperatures but also to the big and resistant spines of the Opuntia ficus-indica. To fulfill the lack of suitable protection equipment for this specific activity, a project emerged with the aim of producing an innovative clothing system composed by textile structures that can act as a barrier to spines and glochids without compromising breathability and presenting a suitable fitting, ergonomics and freedom of movements. This paper will focus on the development of a multilayer clothing system in which the outer layer provide protection against perforation and the inner layer acts like a second skin providing thermal comfort and freedom of movement, so the producers can withstand high temperatures. Concerning the inner layer, several textile structures were developed to analyze the impact on breathability, moisture management and thermal regulation. For the outer layer more than 20 fabrics were developed and submitted to laboratory tests to study their perforation and tearing resistance (according to EN 388). Afterward two structures were selected to proceed and new finishings were developed to prevent the adhesion of the glochids to the textile substrate and simultaneously to give water repellency. Results achieved for the clothing solution from laboratory and field tests with end-users will be presented.
\end{abstract}

\section{Keywords}

protective clothing,

comfort and well-being,

innovative clothing system,

thermo-physiological comfort,

advanced textiles
(C) 2020 The authors. Published by CDAPT.

This is an open access article under the CC BY-NC-ND license https://creativecommons.org/licenses/ peer-review under responsibility of the scientific committee of the CDAPT. 


\section{Introduction}

Originally from México, Opuntia ficus-indica is a cactus species which widespread in both hemispheres and all the continents in arid and semi-arid regions and has been domesticated due to the large potential of these crops in several applications. In fact, Opuntia ficus-indica exploitation potential is almost integral. The cladodes can be used as food for animals and human (juice, jam, pickles etc.) or as natural dyers and thickeners. Concerning Opuntia ficus-indica fruit, it is most widespread uses as a fresh fruit although it can be processed into jam, juice, liquors, vinegar among others. From the seed, oil is extracted used in the cosmetic industry, and from this extraction a by-product is obtained used as animal feed. Finally, after drying the flower it is utilized for infusions with several therapeutically applications [1-3].

The perennial shrub Opuntia ficus-indica can grow up to 5 meters height. It presents succulent stems called cladodes that when they are 1-2 years old can produce flowers. These flowers may have three distinct colors, white, yellow and red, start to appear in May and go through early summer, concerning Northern Hemisphere productions. The Opuntia ficus-indica fruit harvest season is from August to October $[4,5]$

Since Opuntia ficus-indica is typically produced in arid and semi-arid regions and the harvest season goes from August to October, the farmers are exposed to harsh environmental conditions such as high temperatures. Additionally, the farmers are exposed to the cladodes as they may present big and resistant spines as well as glochids, air like spines that easily detach from the plant and lodge in the skin and eyes, causing irritation upon contact [6] [7].

Due to the lack of protection equipment's for this specific activity and in order to improve Opuntia ficusindica producers' protection and comfort, a Portuguese consortium composed by three Portuguese companies and coordinated by CITEVE has joined synergies. Therefore, the main goal of this project is to develop a two-layer protection clothing system in which the outer layer provides main protection against perforation and the inner layer acts like a second skin providing thermal comfort and freedom of movements.

Concerning the inner layer, in order to achieve the thermal comfort needed for the Opuntia ficus-indica producers, after a body mapping analysis, the seamless technology was selected. Several prototypes were made for both men and women with different fiber compositions and different structures designed to each body region needs (ventilation, compression, moisture management, etc.). Besides thermal comfort, it is also important that the underwear provides freedom of movement and practicality to dress and undress. To evaluate the characteristics mentioned above, potential end-users tested the underwear garment during the harvest season of Opuntia ficus-indica fruit, which resulted in the selection of the suitable composition/structures for the underwear garment. The proof of concept was developed in collaboration with Confraria do Figo da Índia (Serpa) and Cactacea (Sesimbra).

In addition of providing protection against perforation, the outer layer will also have easy care features as waterproof and water repellency in order to make it easier to remove the glochids that get attached to the apparel. At first, more than 20 fabrics were developed to analyze the influence of using different parameters (composition, structure and titer of the yarn). Since the main goal is to achieve simultaneously protection and breathability, after submitted to laboratory tests to study their perforation and tearing resistance (according to EN 388) two different structures were selected to proceed and new finishings were developed to prevent the adhesion of the glochids to the textile substrate and simultaneously to give water repellency.

\section{Method}

The research and development process of the materials and textile components of the outer layer initially involved the development of several textile samples with good mechanical performance (tearing and perforation resistance), followed by the optimization of the repellent finishing and, finally, the optimization of the combined solution (waterproof and water repellence). 
Textile Structure

Development and

Selection
Repellent Finishing

Optimization
Combined Solution

Optimization

(Waterproof and Water repellent )

Figure 1. Outer layer development process

On the other hand, the research and development process of the inner layer began with the selection of interesting fibers that could be incorporated in the underwear garment, succeeding with the development of textile structures and afterwards the development of several prototypes that were evaluated by potential end users.
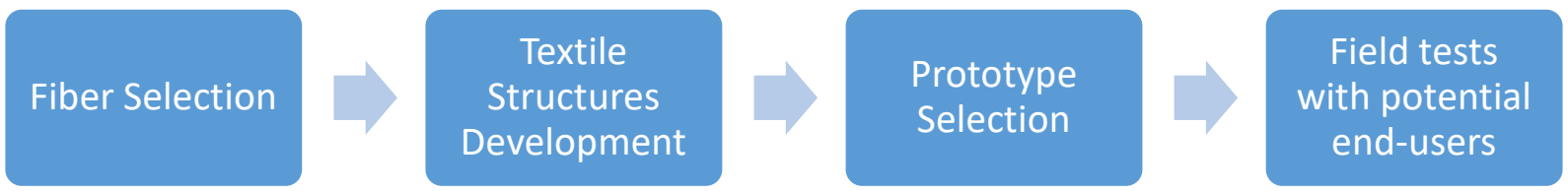

Figure 2. Inner layer development process

With the purpose of evaluating the characteristics required for the outer layer, several laboratorial tests were carried out. Regarding the protection against perforation, there is not currently a standard suitable for protection against spine perforation by Opuntia ficus-indica, thereby for this project was selected the standard EN 388 that is used to certify protective gloves against mechanical hazards. On the other hand, to evaluate easy clean functionalities (waterproof/water repellency), the method selected was the Bundesmann test. Regarding the fabric breathability, it was evaluated by the water vapor resistance. The most important evaluation techniques considered for the outer layer fabric are described in Table 1.

Table 1. Evaluation Techniques for the outer layer

\begin{tabular}{lll}
\hline Factor & Property & $\begin{array}{l}\text { Evaluation } \\
\text { Techniques / Tests / Standards }\end{array}$ \\
\hline & Tearing Resistance & $\begin{array}{l}\text { EN 388 } \\
\text { Protective gloves against } \\
\text { mechanical risks }\end{array}$ \\
\cline { 2 - 3 } $\begin{array}{l}\text { Physical and mechanical } \\
\text { textile properties }\end{array}$ & Puncture Resistance & $\begin{array}{l}\text { EN 388 } \\
\text { Protective gloves against } \\
\text { mechanical risks }\end{array}$ \\
& Waterproofness / Water & EN 29865 \\
& Repellence & Bundesmann \\
\hline $\begin{array}{l}\text { Thermophysiological } \\
\text { wearer comfort }\end{array}$ & Water-vapor resistance & ISO 11092 \\
& & Skin Model \\
\hline
\end{tabular}

Regarding the inner layer, due to the use of a seamless garment with several structures, key features of this layer as thermal regulation, moisture management, breathability, ergonomics and fitting were tested in a real environment with Opuntia ficus-indica workers. For that CITEVE performed comfort, ergonomics and fitting tests in cooperation with Confraria do Figo da Índia (Serpa) and Cactacea (Sesimbra) using questionnaires and interviews as the main techniques.

\section{Results}


The research and development process of the materials and textile components of the outer layer consisted, during the initial stage, in the development of several textile samples, changing the construction parameters, such as fiber/composition, title and filament number of the warp and weft yarns and the structure.

Besides the variation regarding construction parameters, the development of several textile samples was based on some initial considerations. In order to ensure good mechanical properties, namely good perforation and tearing resistance, it was established that the textile structures in the developed samples should have fabric coverage values near $100 \%$. With this consideration, it is intended to guarantee low fabric porosity and consequently increase the mechanical resistance of the fabric. With the purpose of ensuring good mechanical properties without compromising weight and comfort of the textile structures, it was also established that the mass per unit surface area should be between 140 and $220 \mathrm{~g} / \mathrm{m}^{2}$. Finally, for economic and technological reasons, the use of $100 \%$ polyester (PES) for the warp and $100 \%$ polyamide (PA) for the weft yarns in the fabric was considered in all the developed structures.

After the evaluation of the fabric construction parameters regarding the mechanical properties (perforation and tearing resistance), the most promising samples were selected and are described in Table 2.

Table 2. Key construction parameters for the most promising textile structures

\begin{tabular}{lll}
\hline & Sample 4.5 & Sample 6.2 \\
\hline \multirow{3}{*}{ Warp Composition } & $100 \%$ PES & $100 \%$ PES \\
& 150 den & $150 \mathrm{den}$ \\
& 52 yarns $/ \mathrm{cm}$ & 52 yarns $/ \mathrm{cm}$ \\
\hline \multirow{3}{*}{ Weft Composition } & PA $6.6 \mathrm{HT}$ & $\mathrm{PA} 6.6 \mathrm{HT}$ \\
& $235 \mathrm{dtex}$ & $180 \mathrm{dtex}$ \\
& 29 yarns $/ \mathrm{cm}$ & 30 yarns $/ \mathrm{cm}$ \\
\hline Structure & Twill $2 / 1$ & Twill $2 / 1$ \\
\hline Mass per unit area & $184 \mathrm{~g} / \mathrm{m}^{2}$ & $165 \mathrm{~g} / \mathrm{m}^{2}$ \\
\hline
\end{tabular}

With the purpose of evaluating the level of protection guaranteed by the chosen fabrics laboratorial tests were carried out according to the standard EN 388 - Protective gloves against mechanical risks. The results obtained for the fabric samples developed are presented in Table 3.

Table 3. Tearing and perforation resistance of the most promising structures and performance level

\begin{tabular}{llcc}
\hline & & Sample 4.5 & Sample 6.2 \\
\hline $\begin{array}{l}\text { Tearing } \\
\text { Resistance (N) }\end{array}$ & Warp & 32.4 & 49 \\
\cline { 2 - 4 } & Weft & 55.7 & 54 \\
\hline $\begin{array}{l}\text { Perforation } \\
\text { Resistance (N) }\end{array}$ & Tearing & 69.3 & 38 \\
\hline $\begin{array}{l}\text { Performance } \\
\text { Level }\end{array}$ & Perforation & $\mathbf{2}$ & $\mathbf{2}$ \\
\cline { 2 - 4 } & & $\mathbf{2}$ & $\mathbf{1}$ \\
\hline
\end{tabular}

Despite presenting lower values regarding perforation resistance, sample 6.2 is lighter and has better tearing resistance when compared with sample 4.5. Thereby both of the samples can be used with success for the development of the protective clothing for Opuntia ficus-indica producers.

Posteriorly, on a second stage of the process, after selecting the most promising textile structures, the study of functional finishes began. Functional finishings were applied to impart easy clean properties (waterproofness / water repellency) to the fabric, so that the protective clothing developed can be easily cleaned with a shower. Additionally, to prevent the adhesion of glochids to the textile, it is intended that the functional finishing grants a "paper touch" to the fabric. With this in mind, the study and development of functional finishings began by studying the functional property of water repellency and later on obtaining a combined solution, that is, water repellent and waterproof. 
In order to develop a textile with water repellence characteristics four repellent products were chosen and applied in the selected fabric samples (trial 6.2 and trial 4.5), with different concentrations suggested by each supplier. Between the chosen repellents, two of them have fluorocarbons (repellent 1 and repellent 3 ) and the other two are fluorocarbon free (repellent 2 and repellent 4). To evaluate the influence of the selected products and the product concentration regarding the level of repellence imparted to the fabric, the contact angle was measured. To ensure water repellency to the fabric, the contact angle measured using water should be $90^{\circ}$ or superior. The contact angle measuring results have shown that all the selected repellent products impart water repellence to the fabric regardless the concentration used, as can be seen in Figure 3.

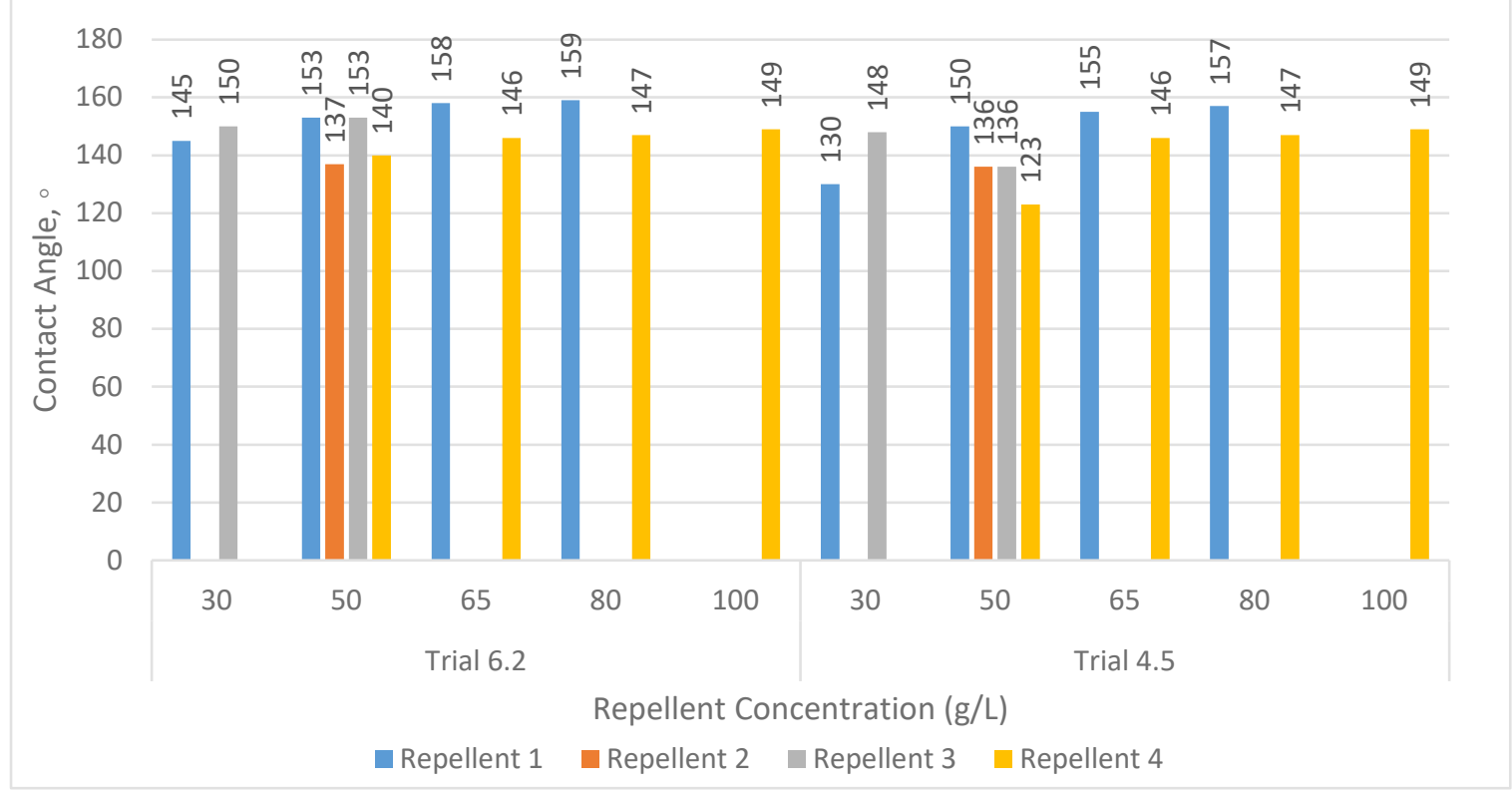

Figure 3.Contact angle measuring results for the repellent products applied with different concentrations

The analysis of the results allowed to conclude that as the concentration increased, the contact angle also increased. Additionally, it was also possible to conclude that fluorocarbon based repellent products present higher contact angles.

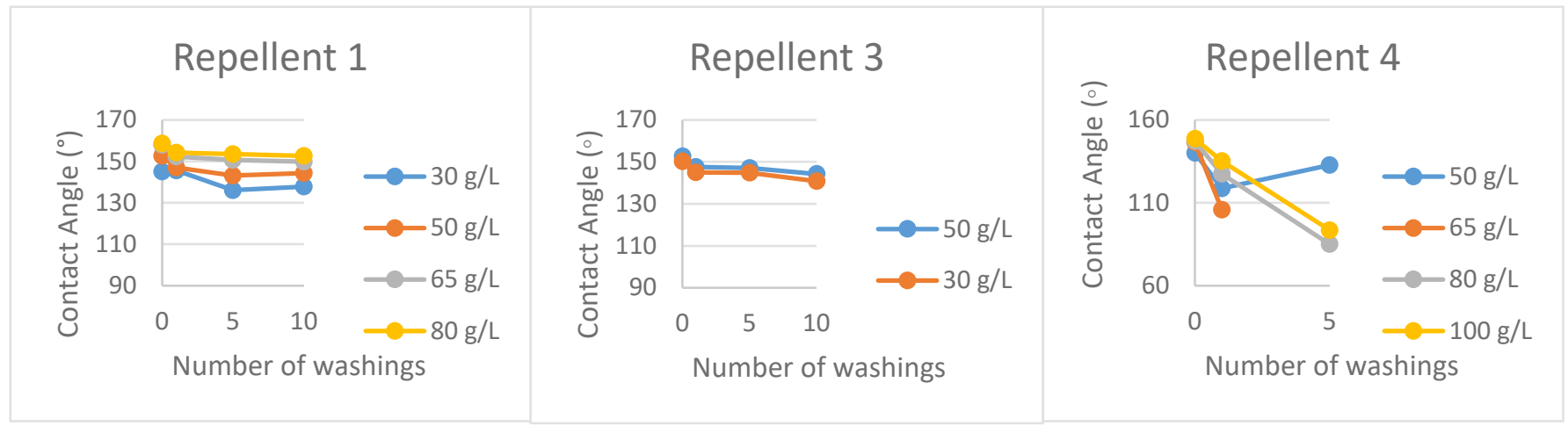

Figure 4. Contact angle results regarding fastness to wash trials for repellent 1, 3 and 4.

Afterwards, fastness to wash trials was carried out in order to understand the influence of washes on fabric repellency after one, five and ten washes. Regarding fluorocarbon free product impregnated samples, the contact angle results have shown a continuous decrease wash after wash. On the other hand, for the fluorocarbon based product impregnated samples after one wash, the contact angle decreased despite staying constant in the remaining washes. Thereby it was possible to conclude that fluorocarbon based 
product impregnated fabrics present better results and the sample impregnated with $30 \mathrm{~g} / \mathrm{L}$ of repellent 3 achieved the most promising result, as can be verified in Figure 4.

Posteriorly, after selecting the water repellent product, the second stage of functional finishing study began. In this stage, the main goal was to obtain a combined solution using the water repellent product selected in the early stage and a waterproof coating that could also improve the mechanical characteristics of the fabric, being a barrier between the worker and the cactus spines.

The waterproof functionality can be obtained through foam or paste coating using a knife over roll system. Paste coating is used when the need exists to cover all the interstices of textile surface in order to achieve a waterproof surface. On the other hand, when there is a need to obtain a textile surface that can be simultaneously breathable and waterproof, foam coating is recommended. Both possibilities were studied; however, since one of the key features is to achieve a paper touch surface to prevent the adhesion of the glochids, the foam coating possibility was discarded since this method grants a smooth touch to the textile surface and the preliminary field tests have shown that it does not prevent the glochids' adhesion. Thereby, regarding paste coating applications, two alternative methods of application were carried out, one of which consists in the application of the coating over the fabric impregnated with water repellent product, and the other in the application of the coating with the water repellent incorporated in the paste formulation. In this stage of the process the two water repellent products with the best results were tested, repellent 1 and repellent 3. No samples were made with repellent 3 incorporated in the paste formulation, as its incorporation resulted in foam formation.

Table 4.Tearing and perforation resistance results for the coated samples

\begin{tabular}{|c|c|c|c|c|c|c|c|c|}
\hline \multirow{2}{*}{ Trial } & \multirow{2}{*}{ Sample } & \multirow{2}{*}{$\begin{array}{l}\text { Impregnation } \\
\text { Formulation }\end{array}$} & \multirow{2}{*}{$\begin{array}{l}\text { Paste } \\
\text { Formulation }\end{array}$} & \multicolumn{3}{|c|}{$\begin{array}{l}\text { Tearing } \\
\text { Resistance (N) }\end{array}$} & \multicolumn{2}{|c|}{$\begin{array}{l}\text { Perforation } \\
\text { Resistance (N) }\end{array}$} \\
\hline & & & & Warp & Weft & Level & $\begin{array}{l}\text { Maximum } \\
\text { strength }\end{array}$ & Level \\
\hline 6.2 & 1 & Repellent 1 & $\begin{array}{l}\text { Binder } 1 \\
\text { Thickener } 1\end{array}$ & 43.4 & 35.0 & 2 & 56.0 & 1 \\
\hline 6.2 & 2 & Repellent 3 & $\begin{array}{l}\text { Binder } 1 \\
\text { Thickener } 1\end{array}$ & 62.8 & 54.1 & 3 & 65.2 & 2 \\
\hline 6.2 & 3 & n. a. & $\begin{array}{l}\text { Binder } 1 \\
\text { Thickener } 1 \\
\text { Repellent } 1\end{array}$ & 25.0 & 18.0 & 1 & 65.0 & 2 \\
\hline 4.5 & 1 & Repellent 1 & $\begin{array}{l}\text { Binder } 1 \\
\text { Thickener } 1\end{array}$ & 48.0 & 75 & 2 & 36.8 & 1 \\
\hline 4.5 & 2 & Repellent 3 & $\begin{array}{l}\text { Binder } 1 \\
\text { Thickener } 1\end{array}$ & 34.5 & 57.8 & 2 & 71.4 & 2 \\
\hline 4.5 & 3 & n. a & $\begin{array}{l}\text { Binder } 1 \\
\text { Thickener } 1 \\
\text { Repellent } 1\end{array}$ & 38.0 & 69.3 & 2 & 62.0 & 2 \\
\hline
\end{tabular}

The best result was achieved by sample 2 for 6.2 , since in this sample a compromise was reached between the tearing and perforation resistance. Afterwards the selected samples were submitted to new laboratorial assays in order to assess whether the coating is waterproof/water repellent (Bundesmann) and at the same time provides thermal comfort (water-vapor resistance) for the end-users. The results obtained are summarized in Table 5.

Despite satisfactory results regarding water penetration resistance, the selected sample did not achieve good results concerning water-vapour resistance, which translates into not obtaining the required thermal comfort for the end-users. Therefore, as the final solution an impregnated fabric will be used as the coverall solution and a coated fabric will be used on the critical areas, in order to reach a compromise between thermal comfort and tearing/perforation resistance. 
Table 5. Water penetration resistance (Bundesmann) and water-vapor resistance results for the coated samples

\begin{tabular}{|c|c|c|c|c|c|c|}
\hline \multirow[b]{2}{*}{ Trial } & \multirow[b]{2}{*}{ Sample } & \multicolumn{4}{|c|}{ Water penetration resistance - Bundesmann Test } & \multirow[b]{2}{*}{$\begin{array}{l}\text { Water- } \\
\text { Vapor } \\
\text { Resistance } \\
\left(\mathrm{m}^{2} \mathrm{~Pa} / \mathrm{W}\right)\end{array}$} \\
\hline & & $\begin{array}{l}\text { Water } \\
\text { Absorption } \\
(\%)\end{array}$ & $\begin{array}{l}\text { Hydrophobicity } \\
\text { Level }\end{array}$ & $\begin{array}{l}\text { Back side } \\
\text { Wetting }\end{array}$ & $\begin{array}{l}\text { Amount of } \\
\text { water that } \\
\text { passes } \\
\text { through the } \\
\text { specimen }(\mathrm{mL})\end{array}$ & \\
\hline 6.2 & 2 & 0.85 & 2 & No & 0.28 & $\geq 200$ \\
\hline
\end{tabular}

Regarding the inner layer development, initially a preliminary selection of structures and materials was made in order to achieve the required properties for this layer such as breathability, moisture management, thermal regulation, microbial protection, odor neutralization, hydration, compressibility, localized ventilation, high resistance to wash, movement freedom and comfort. The multi-functionalities required can be obtained from one or more competing variables in the construction of textiles substrates. These variables can be permanent, which are derived from the material and/or structure, or temporary, derivate from the finishing process, by addition of chemical substances.

For the inner layer, in order to achieve the main features previously described, the development began with the selection of interesting fibers that could be incorporated in the construction of the underwear garment. The selected fibers for the underwear were polyester, polypropylene, wool and polyamide. Polyester and polypropylene fibers have good elasticity, fast dry properties and low humidity absorption. On the other hand, wool fibers are known for their good thermal and humidity management. Easy care properties are associated to both polyester and polyamide fibers. Polyamide fibers are also known for having good chemical resistance, tenacity, high abrasion resistance, low humidity absorption and good touch. All the selected fibers have good dimension stability and durability. The possibility of using elastane fibers was also studied since these fibers have good elongation and recuperation properties in addition of being recommended for seamless technology technic.

Relative to textile structures, in order to achieve the required multi-functionalities, samples using different fibers and yarns were produced. The developed samples were made varying the textile structure and consequently the associated functionality. Afterwards, based on the developed structures, the most appropriate yarns and fibers were selected to be integrated in underwear for both male and female. These prototypes were developed taking in consideration the most suitable functionality for each body part as can be verified by the analysis of Figure 5 .

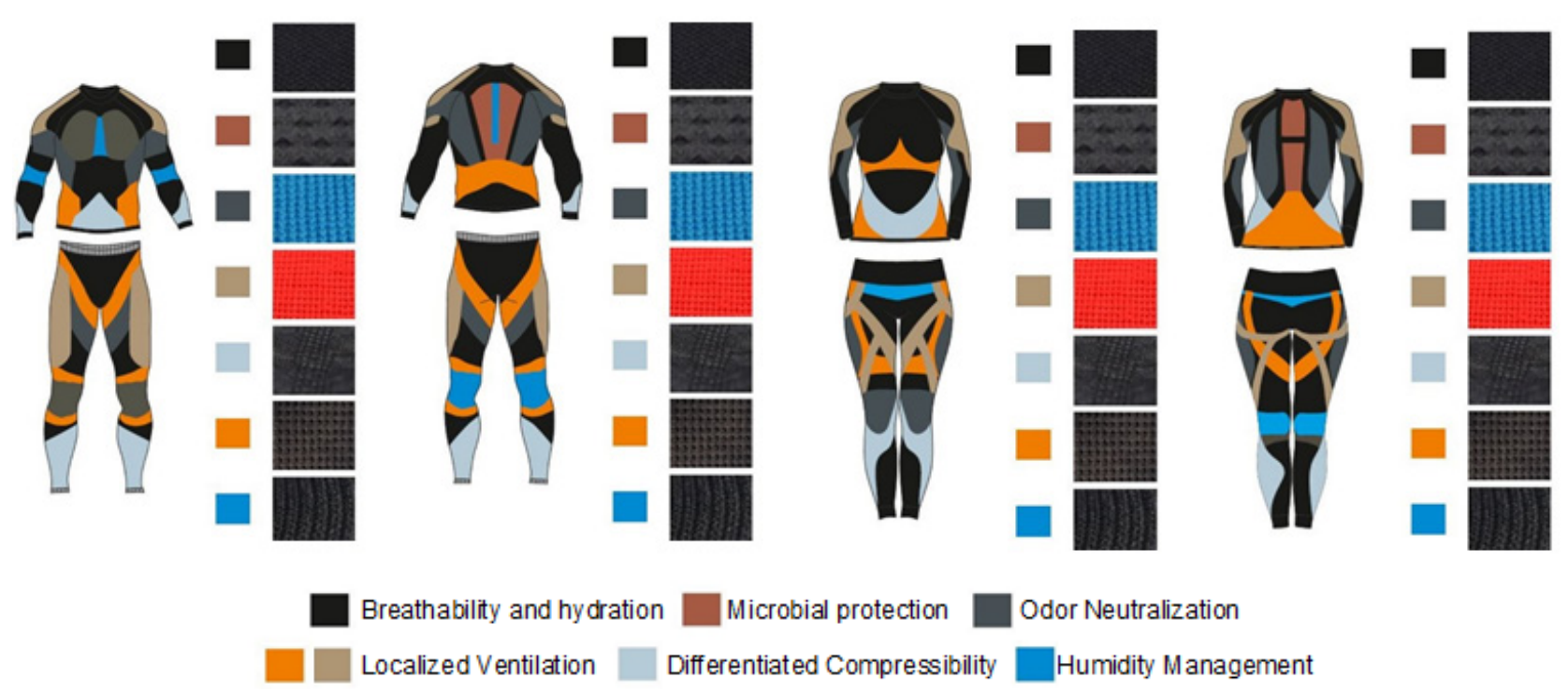

Figure 5. Proposal of design regarding the inner layer accordingly to the location of the functionalities provided by the different structures. 
On an early stage, several prototypes were made using different fiber composition, described in Table 6. These prototypes were evaluated by potential end-users that considered the most promising composition being 53\% WO, 21\% polypropylene, 24\% PA (12\% PA, 12\% PAQ-Skin) and 2\% elastane.

Table 6. Inner layer prototypes compositions

\begin{tabular}{ll}
\hline Prototype & Composition \\
\hline $\mathbf{1}$ & $63 \%$ WO \\
& $37 \%$ PA Q-SKIN \\
$\mathbf{2}$ & $70 \%$ PES Coolmax \\
& $27 \%$ PA Q-Skin \\
& $3 \%$ EA \\
\hline \multirow{3}{*}{3} & $54 \%$ WO \\
& $44 \%$ PA Q-Skin \\
\hline \multirow{2}{*}{4} & $2 \%$ EA \\
& $47 \%$ WO \\
& $53 \%$ PP \\
5 & $53 \%$ WO \\
& $21 \%$ PP \\
& $24 \%$ PA (12 \% PA, 12 \% PA Q-Skin) \\
\hline
\end{tabular}

The chosen underwear has functional properties such as breathability, thermal regulation, humidity management, microbial protection, odor neutralizer, hydration and localized ventilation. The final prototype was evaluated by twenty six potential end-users that tried the underwear between six and ten times.

In Figure 6, it is possible to verify the obtained results regarding the main characteristics of the underwear garment. All the users agreed that the underwear has a very good touch and provides a very good sensation of freshness. At the same time, it was also considered by the users that the underwear garment has good durability and allows freedom of movements. The underwear was also found comfortable and breathable without compromising its wearability with other equipment used on the Opuntia-ficus harvest. On the other hand, the main problem pointed out was the difficulty for dressing and undressing which will be sorted out by adjusting the size charts.

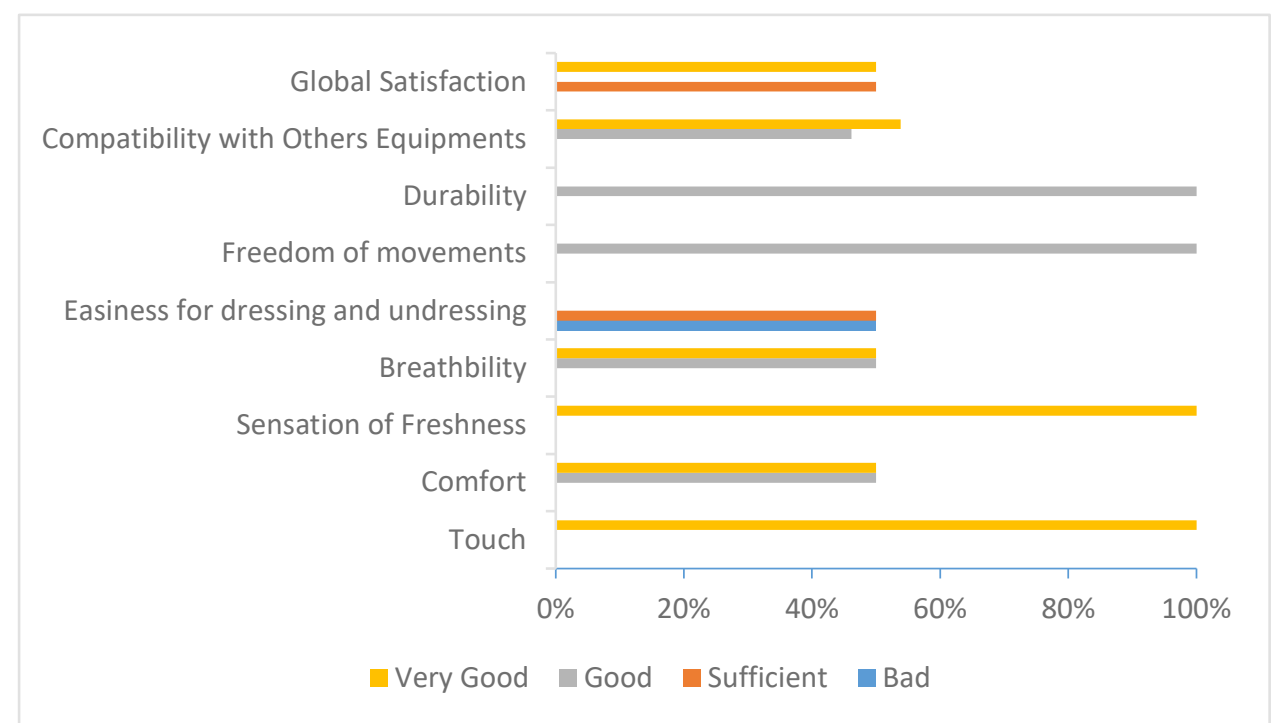

Figure 6. Results obtained regarding the main characteristics of the underwear garment

The survey also questioned about the underwear durability, namely about the fabric elasticity resistance to wash. The underwear was washed by the users from six to ten times and was not reported to show a loss of fabric elasticity. 
Currently, the prototype selected by the end-users is being tested regarding the thermal comfort and moisture management accordingly to the thermal manikin test in order to measure the effect of the materials and textile structures developed.

\section{Conclusions}

In order to fulfill the lack of suitable protection equipment regarding the harvest of Opuntia ficus-indica, it is intended to develop a multilayer suit that can offer both protection and comfort to the workers.

The research regarding the outer layer started with the study of multiple structures in order to achieve a fabric with high tearing and puncture resistance. Afterwards, to grant easy care properties to the selected fabric, four different repellent products were studied (two of them without fluorocarbons). In this study it was possible to conclude that fluorocarbon based products present better results and that the sample impregnated with $30 \mathrm{~g} / \mathrm{L}$ of repellent 3 achieved the most promising result. After selecting the water repellent product, the second stage of functional finishes study began which consisted of obtaining a combined solution using the selected water repellent product and a waterproof coating that can additionally improve the mechanical characteristics of the fabric, being a barrier between the worker and the cactus spines. The selected coating improved the tearing and perforation resistance as well as provided satisfactory water penetration resistance. On the other hand, the selected sample did not achieve good results concerning water-vapor resistance, which translates into not obtaining the required thermal comfort for the end-users. Therefore, the final solution will consist of the use of an impregnated fabric as the coverall solution and a coated fabric on the critical areas, in order to reach a compromise between thermal comfort and tearing/perforation resistance.

Regarding the inner layer development, initially a preliminary selection of structures and materials was made in order to achieve the required properties for this layer. On an early stage several prototypes were made using different fiber composition that were evaluated by potential end-users that selected as final composition $53 \%$ WO, $21 \%$ polypropylene, $24 \%$ polyamide (12\% PA, $12 \%$ PA Q-Skin) and $2 \%$ elastane. The final prototype was evaluated by potential end-users which considered the underwear presents a very good touch and sensation of freedom as well as good durability. The users also found the underwear comfortable and breathable without compromising its wearability with other equipment used on the Opuntia-ficus harvest. The main complaint about the underwear was the difficulty for dressing and undressing which will be sorted out by adjusting the size charts.

\section{Acknowledgements}

This study was supported by COMPETE 2020 / PORTUGAL 2020/ FEDER within TexBoost Project - Less Commodities more Specialties and was made possible thanks to a team of Portuguese partners (CITEVE, DAMEL, LEMAR and OLDTRADING).

\section{References}

[1] Sá, P.; Ramos, J.; Mesquita, A.; Lopes, F., Virgínia Pereira, et al., A. Pela promoção da fileira do figo-da-índia, 2016.

[2] Sáenz, C. Opuntias as a natural resource. In: Sáenz, C. (Ed.) Agro-industrial utilization of cactus pear, Food and Agriculture Organization of the United Nations, Rome, 2013, 1-5.

[3] Barbera, G.; Inglese, P.; Pimienta, E. Agro-ecology, cultivation and uses of cactus pear, Food and Agriculture Organization of the United Nations, Rome, 1995.

[4] da Silva, R. R.; de Sa Barretto Sampaio, E. V. Palmas forrageiras Opuntia fícus-indica e Nopalea cochenillifera: sistemas de produção e usos, Revista GEAMA 2015, 1 (2), 151-161.

[5] Sáenz, C. Chemical composition and characteristics of Opuntia spp, In: Sáenz, C. (Ed.) Agro-industrial utilization of cactus pear, Food and Agriculture Organization of the United Nations, Rome, 2013, 7-16.

[6] Saha, S.; Banerjee, D.; Khetan, A.; Sengupta, J. Epidemiological profile of fungal keratitis in urban population of West Bengal, India, Oman J. Ophthalmol. 2009, 2 (3), 114-118.

[7] Goodheart, H. P.; Huntley, A. C. Rash after visiting Tucson, Dermatology Online Journal, 2001, 7 (2), 10. 